\title{
Microsomal CTP: choline phosphate cytidylyltransferase: kinetic mechanism of fatty acid stimulation
}

\author{
Paul A. Weinhold, Linda G. Charles and Douglas A. Feldman

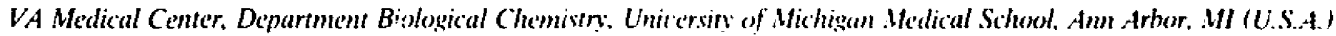 \\ (Received 211 February 1991) \\ (Revised manuscript received 3 June [991)
}

Key words: Fatty acid; Cytidylyltransterase: Phosphatiưylcholine synthesis: Membrane bound enzyme: Enzyme kinetics

Fatty acids are known to cause an increase in the incorporation of radioactive choline into phosphatidylcholine. A coincident increase in membrane cytidylyltransferase activity is well documented. The purpose of the present studies was to determine the direct effects of oleic acid on the kinetic properties of membrane cytidylyltransferase. An examination of the reaction characteristics of membrane cytidylyltransferase revealed that membranes from adult rat lung contained high CTPase activity. This activity prevented the determination of reaction velocities at low CTP concentrations. The CTPase activity was blocked by the addition of ADP or ATP to the reaction. The addition of 6.0 mM ADP to the assay mixture enabled us to determine the effect of oleate on the CTP $K_{m}$. Oleate (122 $\left.\mu: \eta\right)$ caused a significant decrease in CTP $K_{\mathrm{m}}$ for microsomal cytidylyltransferase $(0.99 \mathrm{mM}$ to $0.33 \mathrm{mM})$ and $\mathrm{H}$-Form cytidylyltransferase $(1.04 \mathrm{mM}$ to $0.27 \mathrm{mM})$. Oleate did not decrease the CTP $K_{\mathrm{m}}$ for L-Form cytidylyltransferase. Oleate had no effect on the choline phosphate $K_{m}$ in microsomal, H-Form or L-Form cytidylyltransferase. Oleate also increased the $V_{\max }$ for cytidylyltransferase. The increase was dependent upon the concentration of oleate with a maximal increase of 50-60\% at 100-130 $\mu \mathrm{M}$ oleate. We conclude that oleate has a direct stimulatory effect on cytidylyltransferase when it is in the active form (membrane bound or H-Form lipoprotein complex). We suggest that the kinetic cffects operate synergistically with vihet regulativy mecihanisms such as translocation or conversion of inactive to active species. The direct effect of oleate on the cytidylyltransferase may be an important regulatory mechanism when CTP concentrations are limiting.

\section{Introduction}

CTP: choline phosphate cytidylyltransferase (EC 2.7.7.15) is a major regulatory enzyme in the pathway for phosphatidylylcholine synthesis (reviewed in Refs. 1, 2). Cytidylyltransferase is located in both cytosol ( $100000 \times g$ supernatant; and membranes. The cytosolic enzyme is only partially active and requires the addition of suitable lipids or lipid mixtures for maximal activity (reviewed in Ref, 2). Membrane cytidylyltransferase, on the other hand, has been considered to be fully active since the addition of total lipid extracts to the assay did not increase the activity appreciably [3-9]. However, this conclusion may not be valid in all cases. For example, oleic acid produced nearly a $75 \%$ increase in cytidylyltransferase activity in lung micro-

Correspondence: P.A. Weinhold, Medical Research. VA Medical Center, 2215 Fuller Road, Ann Arbor, M1 48105, U.S.A. somes [10]. A sonicated mixture of phosphatidylcholine and oleic acid (molar ratio of $1: 1$ ) increased cytidylyltransferse activity in membranes from Hep G2 cells by approx. $100 \%$ [1 i]. Kelly et ai. [12] also found that phosphatidylcholine-oleic acid produced a large stimulation of cytidylyltransferase activity in membrane fractions from rat adipocytes. In addition, comparison of the relative ability of phosphatidylglycerol and oleic acid to stimulate cytidylyltransferase activity indicated that oleic acid was a more effective stimulator for membrane cytidylyltransferase, whereas phosphatidylglycerol was more effective for cytosolic enzyme [11]. For membrane cytidylyltransferase. phosphatidylglycerol produces less than half the activity obtained with olcic acid. Thus, the activity of membrane cytidylyltransferase depends upon the type of lipid used in the assay.

Fatty acids have been reported in some instances to increase membrane cytidylyltransferase activity by translocation of cytosolic enzyme to membranes $[13,14]$. 
But in other cases, membrane activity was increased without clear evidence for translocation [3,15-19]. This disparity in results coupled with the possibility that fatty acids may directly influence membrane cytidylyltransferase activity leads to considerable uncertainty as to the mechanisms of the regulatory actions of fatty acids. As part of our efforts to clarify the actions of fatty acids on cytidylyltransferase and phosphatidylcholine synthesis, we examined in more detail the direct effects of fatty acids on membrane cytidylyltransferase activity, The results demonstrated that oleic acid decreased the $K_{\mathrm{m}}$ for CTP and also increased the activity at saturating concentrations of CTP. We obtained these results only after we modified the assay procedure to prevent the interference from high nucleotidase activity in membrane preparations.

\section{Materials and Methods}

\section{Preparation of microsomes and cytosol}

We anesthetized male rats (CDrL VAF, Charles River, $180-220 \mathrm{~g}$ ) with chloral hydrate. We opened the abdominal caviiy and perfused the lung and/or liver with isotonic saline to remove the blood. We homogenized the tissus in $50 \mathrm{mM}$ imidazole $/ 0.15 \mathrm{M} \mathrm{KCl} / 2$ $\mathrm{mM}$ EDTA (pH 7.4) (Buffer A) using $4.0 \mathrm{ml}$ per gram of wet tissue. The homogenate was centrifuged sequentially at $1000 \times g \times 10 \mathrm{~min}, 20000 \times g \times 10 \mathrm{~min}$ and $100000 \times g \times 60 \mathrm{~min}$. We rinsed the surface of the $100000 \times g \times 60$ min pellet (microsomes) in Buffer A. We suspended the pellet in Buffer $A$ (one half the volume of original humogenate). After brief homogenization, the microsomes were collected again by centrifugation at $100000 \times g \times 60 \mathrm{~min}$. The washed microsomes were dispersed in $50 \mathrm{mM}$ imidazole $/ 0.15 \mathrm{M}$ $\mathrm{KCl} / 2 \mathrm{mM}$ EDTA ( $\mathrm{pH} 7.0$ ) to give a final protein concentration of $0.2 \mathrm{mg} / \mathrm{ml}$. The $100000 \times g \times 60 \mathrm{~min}$ supernatant was designated cytosol. All procedures were conducted at $4^{\circ} \mathrm{C}$. We used the Markwell et al. (20) method for protein determination with bovine serum albumin tandards.

Isolation of H-Form, L-Form and microsomes by glycerol density centrifugation

We prepared homogenates as described above. We centrifuged the homogenates at $1000 \times g \times 10 \mathrm{~min}$. The resulting supernatant was centrifuged at $20000 \times g \times 10$ min. The $20000 \times g$ supernatant (postmitochondrial supernatant) was layered on top of a $8 \%-40 \%$ linear glycerol gradient $(1.0 \mathrm{ml}$ on a $10 \mathrm{ml}$ gradient). The preparation of the gradient and the centrifugation conditions have been described previously [21]. The fracions containing H-Forn and L-Form were combined scparately. The microsomes at the bottom of the tube were suspended in Buffer A.
Cytidylyltransferase assay

The standard assay mixture contained $45 \mu \mathrm{l}$ imidazole buffer ( $50 \mathrm{mM}$ imidazole, $2 \mathrm{mM}$ EDTA, pH 7.0), $25 \mu \mathrm{l}$ microsomes in $(50 \mathrm{mM}$ imidazole, $0.15 \mathrm{M} \mathrm{KCl}, 2$ $\mathrm{mM}$ EDTA, $\mathrm{pH} 7.0$ ) and $30 \mu \mathrm{l}$ of a mixture that contained $\left[M e^{14} \mathrm{C}\right]$ choline phosphate $(5.3 \mathrm{mM}, 1000$ $\mathrm{dpm} / \mathrm{nmol}$ ), $10 \mathrm{mM}$ CTP, $40 \mathrm{mM}$ magnesium acetate, $50 \mathrm{mM}$ imidazole, $2 \mathrm{mM}$ EDT A ( $\mathrm{pH} 7.0$ ). This resulted in $100 \mu \mathrm{l}$ containing $1.6 \mathrm{mM}$ choline phosphate, 3.0 $\mathrm{mM} \mathrm{CTP}, 12 \mathrm{mM} \mathrm{Mg}{ }^{2+}$. $50 \mathrm{mM}$ imidazole, $2.0 \mathrm{mM}$ EDTA and $38 \mathrm{mM} \mathrm{KCl}$. We added oleic acid in two ways: (1) oleic acid in hexane was added to a glass tube. The hexane was evaporated with a stream of $\mathrm{N} 2$. We added a volume of $50 \mathrm{mM}$ imidazole, $2 \mathrm{mM}$ EDTA (pH 7.0) to give a final oleic acid concentration of 300 $\mu \mathrm{M}$. We sonicated this mixture for $10 \mathrm{~min}$ with a microprobe sonicator. The appropriate aliquot was added to the assay mixture in place of an equal volume of $50 \mathrm{mM}$ imidazole, 2 mivi EDT $A$, pH 7.0 buffer; and (2) oleic acid was complexed to bovine serum albumin (fatty acid free). We dissolved bovine serum albumin $(10 \mathrm{mg} / \mathrm{ml})$ in $50 \mathrm{mM}$ imidazole, $2 \mathrm{mM}$ EDTA, pH 7.0 buffer. Bovine serum albumin-potassium oleate complexes were prepared as follows. Oleic acid from a stock hexane solution was added to a glass tube and the hexane evaporated with a stream of nitrogen. A volume of $0.8 \mathrm{M} \mathrm{KOH}$ was added which was calculated to titrate the amount of oleic acid. The appropriate volume of $10 \mathrm{mg} / \mathrm{ml}$ bovine serum albumin was added. The mixture was incubated at $55^{\circ} \mathrm{C}$. The moiar ratio of oleic acid to bovine serum albumin was varied from 0.06 to 10.7 . The corresponding concentration of free oleate was calculated using the computer program developed by Wosilait and Nagy [22]. The oleat - -BSA solution $(10 \mu \mathrm{l})$, was added to the reaction nixiure. This resulted in a BSA concentration of $1 \mathrm{mg} / \mathrm{ml}$ in the assay. Control (no oleate) reactions contained 1 $\mathrm{mg} / \mathrm{ml}$ BSA. We mixed microsomes with assay buffer and, when desired, oleic acid or BSA oleate. The mixture was incubated on ice for $6 \mathrm{~min}$. In the preparation of the assay mixture, the oleic acid solution was always added to the assay mixture after microsomes had been added in order to reduce the possible binding of oleic acid to the glass test tube. This was a problem at low oleic acid concentrations in the absence of carrier BSA. We started the reaction by the addition of the CTP/choline phosphate $/ \mathrm{Mg}^{2+}$ mixture and incubated at $37^{\circ} \mathrm{C}$. The reaction was stopped with $10 \%$ TCA containing $150 \mathrm{mM}$ phosphocholine. We added $1.0 \mathrm{ml}$ of charcoal suspension $(6 \mathrm{~g} / 100 \mathrm{ml}$ water) to absorb the CDPcholine as described previously [23].

\section{Measurement of CTP :.:scleotidase}

We prepared a reaction mixture identical to that used for cytidylyltransferase assay except that unlabeled choline phosphate and $\left[{ }^{3} \mathrm{H}\right] \mathrm{CTP}(1 \mu \mathrm{Ci} / 100 \mu]$ 
reaction) were added. The reaction was stopped ly placing the tubes into a boiling water bath. After centrifugation to pellet the precipitated protein, we applied $25 \mu \mathrm{l}$ aliquots to silica gel 60 plates. The plates were developed in methanol/0.9\% $\mathrm{NaCl}$ /concd. $\mathrm{NH}_{4} \mathrm{OH}(10: 10: 1)$. We scraped $1 \mathrm{~cm}$ sections sequentially up the sample lanes, into scintillation vials. Radioactivity was determined in a liquid scintillation spectrometer. The $R_{\mathrm{F}}$ values for CTP, CDP and CMP were $0.56,0.76$, and 0.87 , respectively.

\section{Materials}

All radiochemicals were purchased from New England Nuclear-Du Pont (Wilmington, DE). Bovine serum alhumin (essentially fatty acid-free, Ca: No. A-60u3) was obtained from Sigma Chemical Co.

\section{Results and Discussion}

The effect of oleic acid on the cytidylytiransferase reaction

The accurate determination of cytidylyltransferase activity in homogenates and membrane preparations has been widely recognized to be difficult because of the lack of proportionality of the reaction with time and amount of tissue preparation. Our initial experiments on the oleic acid stimulation of membrane cytidylyltransferase activity suggested that the oleic acid stinulation was associated in some way with the membrane property causing the disproportionate response with time and microsomal protein, Fig. 1. Although oleic acid increased the initial reaction rate, the reaction essentially stopped after $20 \mathrm{~min}$ in both control and oleic acid reactions, Fig. 1A. However, oleic acid extended the proportionality with microsomal protein to rearly $15 \mu \mathrm{g}$ protein compared to $5 \mu \mathrm{g}$ for the control Fig. 1B.

We found that the linearity with time was extended by increasing the CTP concentration. For example, the

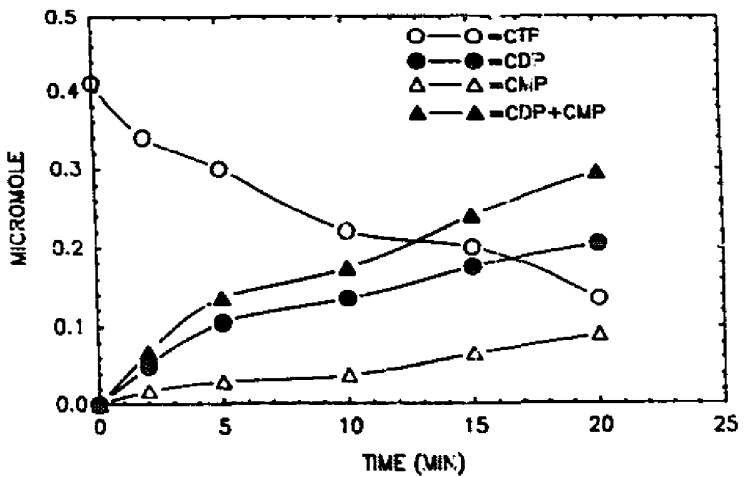

Fig. 2. CTP hydrolysis by lung microsor.es. Each reaction contained $21 \mu \mathrm{g}$ of microsomal protein. The reaction contained $5 \mathrm{mM} \mathrm{[}{ }^{3} \mathrm{H}$ KCTP. The micromoles of product were calculated from percent of the total radioactivity in each compound (\%) $x$ micromoles CTP in the reaction)

reaction rate with $20 \mu \mathrm{g}$ of lung microsomes was constant for nearly $20 \mathrm{~min}$ at $12 \mathrm{mM} \mathrm{CTP} \mathrm{but} \mathrm{at} 3 \mathrm{mM}$ CTP the rate was constant for only 5 min. These results suggested that lung microsomes contained CTPase activity. The presence of enzymes that hydrolyze CTP has been reported previously to cause difficulties in the assay of cytidylyltransferase [24-26].

\section{CTPase acticity in lung microsomes}

We measured the hydrolysis of CTP under conditions identical to those used for the cytidylyltransferase assay. Under these conditions, microsomes catalyzed a rapid hydrolysis of CTP to CDP, Fig. 2. In separate experiments, the CTPase activity, measured from the formation of $\left[{ }^{3} \mathrm{H}\right] \mathrm{CDP}$ plus $\left[{ }^{3} \mathrm{H}\right] \mathrm{CMP}$ after $10 \mathrm{~min}$ reactions with $300 \mathrm{nmol}\left[{ }^{3} \mathrm{H}\right] \mathrm{CTP}$, was determined to be $19.0 \pm 3.5 \mathrm{nmol} / \mathrm{min} / 20 \mu \mathrm{g}$ microsomal protein. Thus, aiter $10 \mathrm{~min}$, approx. $63 \%$ of the CTP was hydrolyzed. This rate of CTP hydrolysis together with the utilization of CTP by the cytidylyltransferase reac-
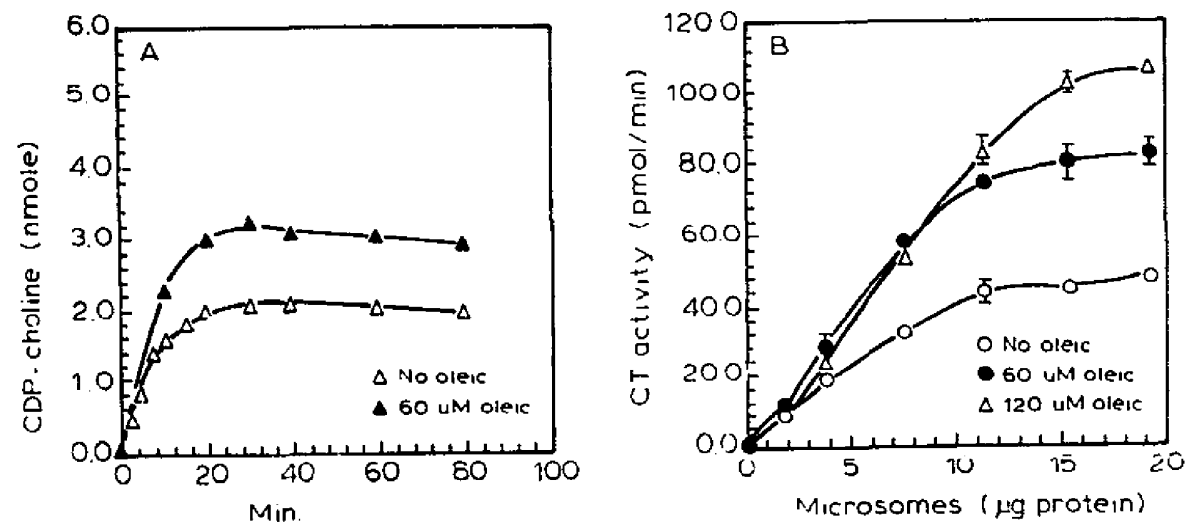

Fig. 1. Effect of oleic acid on the reaction properties of membrane cytidylyltransferase. (A) Reaction vs.. time with $35 \mu \mathrm{g}$ lung microsomal protein per reaction. (B) Reaction vs. lung microsomal protein. A 30 min reaction time was used. 
tion would result in nearly complete depletion of CTP after $30 \mathrm{~min}$.

In view of the previous reports that oleic acid caused a decrease in the CTP $K_{\mathrm{m}}$ for cytidylyltransferase in liver cytosol [13], it seemed likely that a similar effcct may occur with the microsomal enzyme. Since an accurate determination of the CTP $K_{\mathrm{m}}$ could not be obtained in the presence of high CTPase activity, we examined conditions for the prevention of CTPase activity. The CTPase activity was reduced by $3.0 \mathrm{mM}$ ATP to $8.1 \mathrm{nmol} / \mathrm{min}$ per $20 \mu \mathrm{g}$ protein. ADP $(6.0$ $\mathrm{mM}$ ) reduced the CTPase to $3.7 \pm 0.5 \mathrm{nmol} / \mathrm{min}$ per $20 \mu \mathrm{g}$ protein. We obtained further verification that the deplction of CTP by CTPase caused the reductions in the cytidylyltr.usferase reaction. We measured the formation of CDP choline with time in the presence of either $3.0 \mathrm{mM}$ ATP or $3.0 \mathrm{mM}$ ADP. Under these conditions, CDP choline production was linear for 60 min compared to only $5 \mathrm{~min}$ without ATP or ADP. AMP was not active in this regard. The oleic acid effect shown in Fig. 1 was not caused by CTPase inhibition since oleic acid did not inhibit the hydrolysis of CTP $(20.2 \pm 1.9 \mathrm{nmol} / \mathrm{min}$ per $20 \mu \mathrm{g}$ of microsomal protein in the presence of $60 \mu \mathrm{M}$ oleic acid). Neither $100 \mathrm{mM}$ fluoride or $2.0 \mathrm{mM}$ orthovanadate extended the period of linear CDPcholine production beyond that of the control. Furthermore, fluoride did not inhibit the CTP ise activity. These resuits suggest that the CTPase is probably a nucleotidase and not a nonspecific phosphatase.

\section{Kinctics of oleic acid stimulation}

We now were able to determine the apparent $K_{\mathrm{m}}$ for CTP and choline phosphate in the presence and absence of oleic acid. One difficulty in assessing the effects of low concentrations of oleic acid was the tendency for oleic acid to bind to the glass surface of the reaction tube. This produced erratic results at low concentrations of oleic acid. This problem was eliminated by using oleic acid-bovine serum albumin complexes. The molar ratio of oleic arid to albumin was varied resulting in different concentrations of free oleic acid. The actual concentration was calculated by a computer program (see Materials and Methods). We added $6.0 \mathrm{mM}$ ADP to all assays. Representative kinetic plots for cytidylyltransferase activity versus CTP concentration are shown in Fig. 3. Two types of membrane preparations were used. Both were isolated by glycerol gradient centrifugation. The data in Fig. 3A was obtained from microsomes isolated from $20000 \times g$ $\times 10$ min supernatants maintained at $4^{\circ} \mathrm{C}$. The data in Fig. 3B was obtained from $20000 \times g \times 10$ min supernatants which had been incubated at $37^{\circ} \mathrm{C}$ for $10 \mathrm{~min}$ prior to the isolation of microsomes. This treatment causes translocation of cytosolic cytidylyltransferase to membranes [21] and therefore increases the membrane activity. In both preparations, oleic acid caused a decrease in the apparent $K_{\mathrm{m}}$ for CTP. Three additional experiments were performed. The average $K_{\mathrm{m}}$ was $0.99 \pm$ S.E. $0.07 \mathrm{mM}$ for control (without oleate) anci $0.33 \pm$ S.E. $0.04 \mathrm{mM}$ with oleate. These values were significantly different $P<0.001$. The $K_{\mathrm{m}}$ values for $4^{\circ} \mathrm{C}$ microsomes and $37^{\circ} \mathrm{C}$ microsomes were similar (with or without oleate). The $K_{m}$ for choline phosphate was $0.52 \pm 0.05$. Oleic acid did not change the $K_{\mathrm{m}}$ (data not shown). It is possible that ADP could effect the CTP $K_{m}$. However, ADP was needed to protect the CTP from hydrolysis. Therefore, we could not test this possibility. In any case, any ADP effects would not change the oleic acid results because ADP was present in both control and oleic acid reactions. The oleic acid induced decrease in CTP $K_{m}$ provides a reasonable explanation for the oleic acid effects observed in the presence of high CTPase activity (Fig. 1).
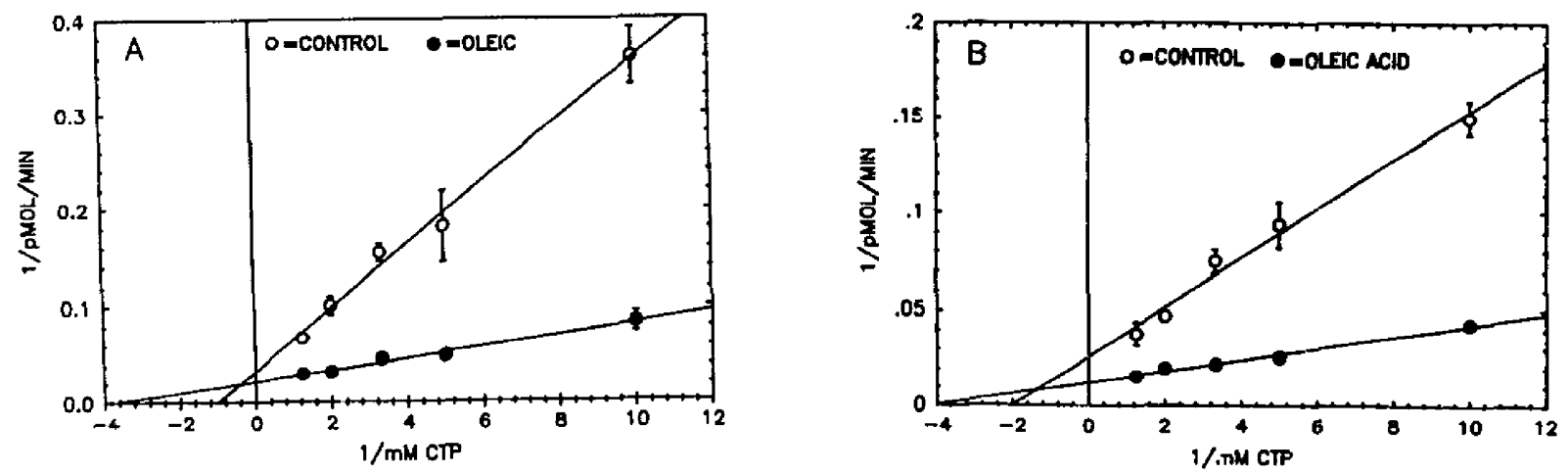

Fig. 3 The effect of oleic acid on СГР $K_{\mathrm{m}}$ for cyticylyluransferase in lung microsomes. Microsomes were isolated by glycerol density gradient centrifugation. All reartions contained $15 \mu \mathrm{g}$ of microsomal protein. (A) microsomes isolated from $4^{\circ} \mathrm{C} 20000 \times g$ supernatant. (B) microsomes isolated from 20000 supernatant incubated $10 \mathrm{~min}$ at $37^{\circ} \mathrm{C}$. Potassium oleate was added as an albumin complex that resulted in $122 \mathrm{mM}$ free oleate. The values are averages of triplicate assays \pm S.D. Where no bar is present, the standard deviation was less than the size of the data symbol. 
In addition to membrane cytidylyltransferase, two furms of cytidylyltransferase are recovered in adult lung cytosol; L-Form that is essentially inactive without lipiu in the assay and H-Form that is about $60 \%$ active without additional lipid [21]. We isolated these forms from cytosol by glycerol density centrifugation. The apparent $2 \mathrm{IP} K_{\mathrm{m}}$ for H-Form cytidylyltransferase was also decreased by oleic acid $(1.04 \mathrm{mM}$ without oleate and $0.27 \mathrm{mM}$ with oleate). These $K_{\mathrm{m}}$ values are nearly identical to those for microsomal cytidylyltransferase. We suggested previously that the active form of cytidylyltransferase is a lipoprotein containing the apoprotein and phospholipids [27]. The apoprotein appeared to be the L-Form consisting of two $45000 \mathrm{M}_{\mathrm{r}}$ ssbunits. Evidence was also presented suggesting that $\mathrm{H}$-Form and membrane cytidylyltransferase were similar lipoprotein forms of the enzyme. The present observation that oleate caused a similar decrease in CTP $K_{\mathrm{m}}$ for H-Form and microsomal cytidylyltransferase provides further support for this conclusion.

Oleic acid appeared not to change the apparent ATP $K_{\mathrm{m}}$ for L-Form of cytidylyltransferase. Since LForm cytidylyltransferase is inactive without lipid in the assay, a direct comparison of the effects of oleate on CTP $K_{\mathrm{m}}$ values was not possible. However, we determined the effect of oleate at suboptimal concentrations of phosphatidylglycerol, $(25 \mu \mathrm{M})$, a lipid that produces nearly maximal activity when added at optimal concentrations $(150 \mu \mathrm{M})$. Under these conditions, oleate did not change the CTP $K_{\mathrm{m}}$ ( $C 67 \mathrm{mM}$ without oleate, $0.75 \mathrm{mM}$ with oleate). The apparent $K_{\mathrm{m}}$ values for choline phosphate were similar for both H-Form and L-Form $(0.3-0.5 \mathrm{mM})$. The choline phosphate $K_{\mathrm{m}}$ values were not changed by oleate. These results suggest that oleate modulation of the CTP kinetics requires cytidylyltransferase to be organized in its active lipoprotein complex. Although phosphatidylglycerol produces stimulation of L-Form cytidylyltransferase activity, the phosphatidylglycerol-L-Form complex apparently does not have the same properties as the native lipoprotein complex. On the other hand, it has been reported that total phospholipid from liver [28] or oleic acid [13] caused a decrease in the CTP $K_{\mathrm{m}}$ for cytidylyltransferase in liver cytosol. Since L-Form cytidylyltransferase is the apparent predominant species in liver cytosol, it might be expected that the response to oleate would be similar for liver cytosol and isolated L-Form. It seems likely that cytosol preparations contain lipids and/or proteins that enable a more native lipoprotein complex to form during lipid stimulation. The isolation of L-Form may remove these factors.

The double reciprocal plots in Fig. 3 indicated that oleate also increased the $V_{\text {max }}$ for cytidylyltransferase. Further experiments on the effects of oleic acid on the velocity of the reaction indicated that maximal stimulation was achieved at $120 \mu \mathrm{M}$ oleate, Fig. 4 . Concentra-

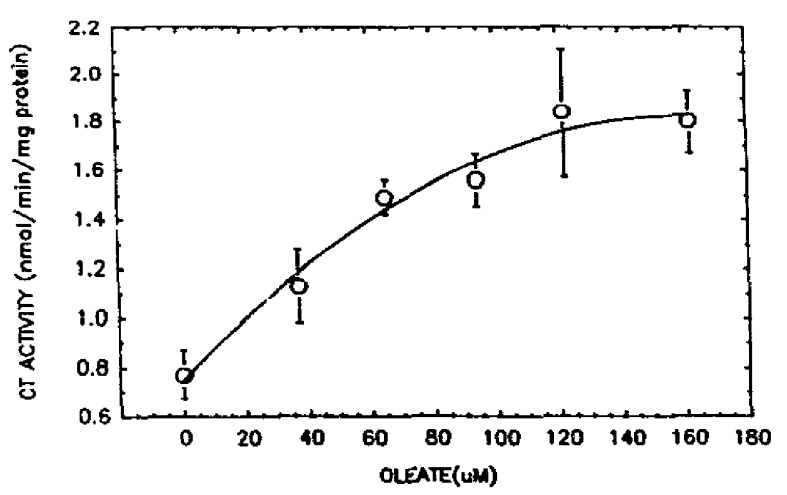

Fig. 4. Microsomal cytidylyltransferase activity versus oleate concentration. Oleate was added as an albumin complex. The molar ratio of albumin/oteate was varied to give the desired concentration of free

oleate. All reactions contained $0.1 \%$ bovine serum albumin.

tions above $120 \mu \mathrm{M}$ produced inhibition. For example, enzynie activity at 200 to $250 \mu \mathrm{M}$ oleate was nearly $50 \%$ lower than activity at $120 \mu \mathrm{M}$ oleate (data not shown).

In conclusion, we presented evidence that fatty acids have a direci effect upon cytidylyltransferase located in microsomal membranes. Oleate caused both a decrease in CTP $K_{\mathrm{m}}$ and an increase in the $V_{\max }$. Membrane cytidylyitransferase activity was increased $50-$ $60 \%$ at saturating concentrations of CTP. In addition, the CTP $K_{\mathrm{m}}$ was decreased nearly 3-fold. The results suggest that fatty acids exert their effects on the active lipoprotein form of cytidylyltransferase. Since the kinetic effects of fatty acids occurred in addition to any action that promoted translocation or conversion of inactive forms of the enzyme, these effects would provide additional regulation of cytidylyltransferase in response to reduced concentrations of CTP. The oleateinduced decrease in CTP $K_{\mathrm{m}}$ is consistent with other result: suggesting that CTP cuncentrations may regulate cytidylyltransferase activity under certain conditions [29].

\section{Acknowledgements}

This work was supported by the Department of Veterans Affairs and by Grants HD 21992 and HD 02871 from the National Institute of Child Health and Human Development.

\section{References}

1 Tijburg, L.B.M., Geelen, M.J.H. and Van Golde, L.M.G. (1989) Biochim. Biophys. Acta 10144, 1-19.

2 Pelech, S.L. and Vance, D.E. (1984) Biochim. Biophys. Acta 779, 217-251.

3 Whitlon, D.S., Anderson, K.E. and Mueller, G.C. (1985) Biochim. Biophys. acta 835, 369-377.

4 Terce, F., Record, M., Ribbes, G., Chap, H. and Douste-Blazy, L. (1988) J. Biol. Chem. 262, 3142-3149. 
5 Cornell, R. and MacLennan, P.H. (1985) Biochim. Biophys. Acta $835,567-576$.

6 Maejd, M., Nishijina, M., Akamatsu, Y. and Sakakibara, Y. (1985) J. Biol. Chem. 260, 5925-5930.

7 Pelech, S.L., Paddon, H.B. and Vance, D.E. (1984) Biochim. Biophys. Acta 795, 447-451.

8 Sleight, R. and Kent, C. (1983) J. Biol. Chem. 258, 831-835.

9 Oldenborg, V. and van Golde, L.M.G. (1977) Biochim. Biophys. Acta 489, 454-465.

10 Weinhold, P.A., Rounsifer, M.E., Williams, S.E., Brubaker, G. and Feldman, D.A. (1984) J. Biol. Chem. 259, 10315-10321.

11 Weinhold, P.A., Charles, L, Rounsifer, M.E. and Feldman, D.A. (1991) J. Biol. Chem. 266, 6093-6100.

12 Kelly, K.L., Gutierrez, G. and Martin, A. (1988) Biochem. J. 255, 693-698.

13 Pelech, S.L., Pritchard, P.H., Brindley, D.N. and Vance, D.E. (1983) J. Biol. Chem 258, 6782-6788.

14 Pelech, S.L., Cook, H.W., Paddon, H.B. and Vance, D.E. (1984) Biochim. Biophys. Acta 795, 433-440.

15 Aeberhardi, E.E., Barrett, C.T., Kaplan, S.A. and Scott, M.L. (1986) Biochim. Biophys. Acta 875, 6-11.

16 Chander, A. and Fisher, A.B. (1988) Biochim. Biophys. Acta 958, 343-351.

17 Burkhardt, R., Von Wichert, P., Batenburg, J.J. and Van Golde, L.M.G. (1988) Biochem. J. 254, 495-500.
18 Mock. T., Slater, T.L., Arthur, G., Chan, A.C. and Choy, P.C. (1986) Biochem. Cell Biol. 64, 413-417.

19 Blank, M.L., Lee, Y.J., Cress, E.A. and Snyder, F. (1988) J. Biol. Chem. 263, 5656-5661.

20 Markwell, M.K., Haas, S.M., Bieber, L.L. and Tolbert, N.E. (1978) Anal. Biochem 87, 206-210.

21 Weinhold, P.A., Rounsifer, M.E., Charles, L. and Feldman, D.A. (1989) Biochim. Biophys. Acta 1006, 299-310.

22 Wosilait, W'.D. and Nagy, P. (1976) Comp. Prog Biomed. 6, 142-148.

23 Feldman, D.A. and Weinhold, P.A. (1987) J. Biol. Chem. 262 , 9075-9081.

24 Wilgram, G.T. and Kennedy, E.P. (1963) J. Biol. Chem. 238, 2615-2619.

25 Ansell, G.B. and Chojnacki, T., (1966) Biochem. J. 98, 303-310.

26 Schneider, W.C. and Behki, R.M. (1963) J. Biol Chem. 238, 3565-3571.

27 Feldman, D.A., Rounsifer, M.E., Charles, L. and Weinhold, P.A. (1990) Biochim. Biophys. Acta 1045, 49-57.

28 Pelech, S.L. and Vance, D.E. (1982) J. Biol. Chem. 257, 1419814202.

29 Vance, D.E., Trip, E.M. and Padden, H.B. (1986) J. Biol Chem. $1064-1069$. 